\title{
“Com muitos dedos puxamos as cortinas para trás": Invisibilidade e silenciamento na poesia feminina contemporânea brasileira
}

\author{
Ana Bessa Carvalho \\ Universidade do Minho
}

Resumo: Este artigo visa uma breve análise de poemas escritos por mulheres brasileiras contemporâneas cujo trabalho denuncia a violência de género, ao apresentar a exploração do desejo (lésbico) como uma das formas de contrariar o silenciamento e a invisibilidade que é comum a todas as autoras a tratar. Serão analisados excertos de poemas de Angélica Freitas, Adelaide Ivánova e outras vozes recentes à luz de teorias de género, à medida que se tenta desenhar um espaço seguro alternativo para estas mulheres fora do padrão da voz poética normativa. Para além do desejo lésbico, ponto central destes poemas, será também dado enfoque à violência contra as mulheres, tema este que está intimamente relacionado com a orientação e identidade sexual, tendo em conta a posição de uma 'dupla segregação' da mulher cujo comportamento sexual não é normativo (a mulher lésbica, a mulher transexual).

Palavras-chave: poesia brasileira; violência de género

\begin{abstract}
This article aims at a brief analysis of poems written by contemporary Brazilian women writers whose work has been denouncing gender violence, by presenting (lesbian) desire as a way to contradict the silencing and the invisibility which is common to all the writers that will be studied. Excerpts of poems by Angélica Freitas, Adelaide Ivánova and other authors will be analysed, through the lenses of gender theories, in order to explore the creation of an alternative safe space for these women outside the pattern of the normative poetic voice. Themes such as lesbian desire and violence against women will be addressed, since


they are intimately related to sexual orientation and identity, taking into consideration the "double segregation" of the women whose sexual behaviour and identification is not normative (the lesbian woman, the transexual woman).

Keywords: Brazilian poetry; gender violence

Na edição de 2016 do Festival NOS Primavera Sound, Elza Soares, uma cantora brasileira cujo último álbum, altamente politizado e engajado, a trouxe de volta aos palcos e aos media, dedicou o tema "Benedita" a Gisberta, uma mulher transexual que se tornou num ícone e símbolo da luta nacional contra a transfobia, morta naquela mesma cidade onde o festival teve lugar. Em "A Mulher do Fim do Mundo", Elza apresenta-se cansada mas não derrotada, pronta para, já octogenária, explorar a sua própria sexualidade, e usar o seu corpo como arma política e o desejo sexual como forma de resistência, ao mesmo tempo que denuncia o Brasil de hoje, marcado pela misoginia, racismo, homofobia e violência policial, assim como por números altíssimos de assassinatos de mulheres transexuais, aos quais Gisberta tentou escapar quando veio para Portugal, onde conheceu um fim tão trágico como o das suas irmãs brasileiras: após ser agredida durante dias por catorze homens - e não é relevante nem os torna impunes que fossem menores de idade -, Gisberta, ainda viva, foi atirada para um poço onde morreu afogada. Em tribunal, foi a água do poço a culpada pela morte desta mulher; os catorze rapazes responsáveis pela sua morte saíram em liberdade. Gisberta é mais do que uma das muitas mulheres transexuais mortas de forma violenta: sendo mulher, imigrante, sem abrigo, trabalhadora sexual e seropositiva, Gisberta levanta questões prementes sobre a fragilidade de vários grupos identitários aqui confluentes no mesmo corpo violentado.

É assim relevante evocar o espetáculo de Elza e a sua lembrança de Gisberta perante uma plateia que poderá ter esquecido a morte trágica desta mulher; recordar Gisberta no início deste ensaio tem como função evocar uma das questões centrais desenvolvidas nas próximas linhas: a violência de género. É de salientar que aqui se pensa o género sempre 
em articulação com as demais categorias identitárias e em interseccionalidade. Para além do trabalho de Elza, serão analisados poemas de Angélica Freitas (1973-) e Adelaide Ivánova (1982-) em articulação com teorias queer sobre a visibilidade e invisibilidade da mulher, nas várias acessões e identificações em que pensamos o sexo feminino e as suas várias possibilidades sexuais.

Em 2006, no mesmo ano em que Gisberta morria no Porto, o Brasil aprovava a Lei Maria da Penha, com o intuito de proteger as mulheres vítimas de violência doméstica e de ser mais eficaz na prevenção destes casos, contrariando a impunidade que é comum aos criminosos. Esta lei foi resultado da luta de Maria da Penha por justiça, uma mulher que sofreu abusos físicos e psicológicos às mãos do marido durante vinte e três anos e que foi ainda vítima de duas tentativas de assassinato por parte deste. Na música "Maria da Vila Matilde”, do mesmo álbum já referido, Elza Soares evoca a criação desta lei, celebrando a possibilidade da mulher em denunciar o crime de violência doméstica, repetindo, "cê vai se arrepender de levantar a mão pra mim", pondo assim um fim simbólico aos anos de repressão, silenciamento e vitimização da mulher dentro do espaço doméstico.

Este tema é também abordado por Adelaide Ivánova, poeta contemporânea nascida no Recife, cuja coleção $O$ Martelo é dedicada a denunciar casos de violência de género tais como a violência doméstica e a violação. 0 martelo do título refere-se à ferramenta que a mulher coloca debaixo da almofada enquanto dorme para que possa proteger-se de um possível e omnipresente abusador:

\author{
Durmo com um martelo \\ Embaixo do travesseiro \\ Caso alguém entre de novo \\ E sorrateiro (Ivánova 2018: s/p)
}

Em “para laura", Ivánova relembra uma jovem transexual, Laura Vermont, que morreu a 20 de Junho de 2015 em São Paulo, depois de ter sido espancada por cinco homens que continuaram ilesos quando o caso foi levado a tribunal. 0 crime foi gravado e depois divulgado em várias redes sociais, tendo sido ainda provado o envolvimento das 
autoridades policiais na morte de Laura, já que o seu corpo apresentava um ferimento de bala disparado por um polícia. Este mesmo polícia pagou ainda a um homem para que este se apresentasse como testemunha e corroborasse uma história falsa sobre uma Laura violenta que atacara os polícias, deixando-os sem outra hipótese a não ser disparar sobre a jovem mulher transexual. No poema, Ivánova escreve:

\author{
em 1998 quando encontraram \\ o corpo gay de matthew shepard \\ sua cara tinha sangue por todo lado \\ menos duas listras \\ perpendiculares \\ que era por onde suas lágrimas \\ haviam escorrido \\ naquele dia o ciclista \\ que o encontrou não \\ ligou para polícia logo que o viu \\ porque o corpo de matthew \\ estava tão deformado \\ que o ciclista achou ter visto \\ um espantalho \\ sábado passado em são paulo \\ a polícia matou laura \\ não sem antes \\ torturá-la laura \\ foi filmada ainda viva \\ por outro sujeito \\ que em vez de ajudá-la \\ postou no youtube o vídeo \\ d'uma laura desorientada \\ e quem não estaria \\ tendo sangue na boca e na parte \\ de trás do vestido
}




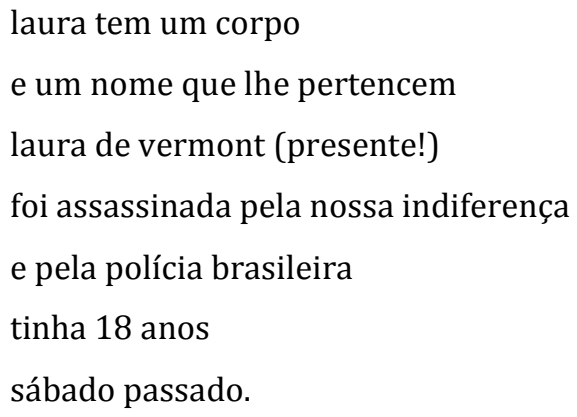

Em "para laura", Ivánova relembra também Matthew Shepard, um jovem rapaz que se tornou, tragicamente, num símbolo da homofobia. À semelhança do que acontecera com Maria da Penha, o caso de Matthew Shepard deu origem a um grande debate público e levou à atualização de leis, neste caso a do crime de ódio, nos Estados Unidos, após uma longa batalha judicial nos tribunais por parte da mãe do jovem rapaz torturado e assassinado por dois homens. Laura está "presente" e não invisível, tem corpo e nome e a sua imagem está gravada na memória coletiva, assim como nos vídeos que circularam pelas redes sociais, apesar de ser pertinente relembrar Susan Sontag e o seu texto Regarding the Pain of Others, quando esta questiona se a constante presença de imagens de sofrimento e dor cria empatia ou apatia, dado que estas imagens também paralisam e anestesiam (Sontag 2004: 102).

Num poema de Angélica Freitas, "mulher depois", Freitas dedica a sua atenção à mulher transexual. Na última estrofe deste poderoso poema, a voz do poema, uma mulher transexual, explica à sua família que não é preciso aceitá-la nem sequer olhar para ela, refutando assim que, para ser visível, terá de ser vista pelo Outro; a identificação sexual de cada uma surge assim de si própria, independentemente da aceitação ou visão do Outro:

\footnotetext{
pois agora eu virei mulher

me operei e virei mulher

não precisa me aceitar

não precisa nem me olhar

mas agora eu sou mulher

(Freitas 2017: s/p)
} 
Esta visibilidade leva-nos à análise de um poema de Angélica Freitas que visa uma outra mulher - a mulher lésbica:

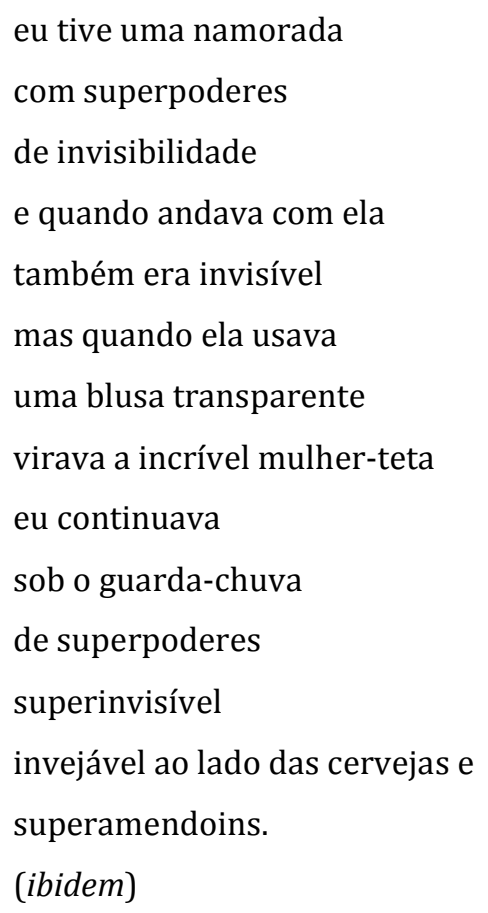

Várias dinâmicas de representação e representatividade estão presentes no poema de Angélica Freitas. Segundo Annamarie Jagose, em Inconsequence: Lesbian Representation and the Logic of Sexual Sequence, os estudos lésbicos prendem-se com a invisibilidade da mulher lésbica, com a sua existência em sequência (primeiro a heterossexualidade, depois a homossexualidade) e sempre em relação à masculinidade (Jagose 2002: 2). Se a lésbica não é um homem gay (como defende Terry Castle em The Apparitional Lesbian) e se a lésbica não é sequer uma mulher (como defende Monique Wittig em The Straight Mind), o que é a mulher que gosta de outras mulheres dentro de uma matriz heteronormativa e falocêntrica? Segundo Jagose, a mulher lésbica é a figura mais compreensivamente trabalhada pela sequência, como não tendo ordem própria, como uma derivação de formas de organização sexual mais primárias e o seu perfil cultural depende assim da sua natureza derivativa secundária, sendo representada sempre em termos de "derivation, imitation, and secondariness. [...] [And] occluded from major critical frameworks, marginalized in the 
fields in which it figures, and deemed irrelevant to key disciplinary questions" (Jagose 2015: 32). ${ }^{1}$

Jagose defende que, para entender a complexidade e as possibilidades da identidade lésbica, é necessário ir além da questão sempre presente da visibilidade e contestar a sua eficácia como medida única de legitimação sexual, já que a abordagem que defende a visibilidade e o reconhecimento por parte do Outro parte da mesma lógica que os estudos lésbicos contestam (ibidem). Esta posição foi já sustentada por Adrienne Rich no seu ensaio fulcral para a discussão da identidade feminista e lésbica dos anos 80, “Compulsory Heterosexuality and Lesbian Existence": "[F]eminist research and theory that contributes to lesbian invisibility or marginality is actually working against the liberation and empowerment of woman as a group" (Rich 2003: 26). ${ }^{2}$

Ser visível implica o reconhecimento do Outro, estando a mulher lésbica assim sujeita a mais uma lógica de derivação e sequência. Voltando ao poema de Angélica Freitas, importa notar que a incrível namorada com poderes de invisibilidade - como todas as namoradas de mulheres, já que estas não podem existir como seres sexuais dentro da matriz de pensamento heterossexual masculino - torna-se visível apenas quando veste a blusa transparente. Aí passa a fazer parte dessa mesma lógica sexual falocêntrica: hipervisível como objeto sexual e sujeita ao male gaze, deixando de existir como mulher lésbica para existir apenas como encorporamento do desejo do homem, enquanto a voz do poema, ao lado das cervejas e dos amendoins e do que é masculino, permanece 'superinvisível'.

Assim, a visibilidade aparece apenas como uma forma de inserção na lógica sexual heteronormativa, uma lógica em que se é visível, mas não reconhecida, tal como Jagose afirma. Em vez da (in)visibilidade, sugiro que nos concentremos na presença visível: presença na imaginação coletiva, nos espaços públicos e privados, nos discursos oficiais, na História, sem que o público reconheça quem está diante de si. Em The Apparitional Lesbian, Terry Castle refere-se à lésbica como uma figura espectral, vítima de um dito ghost effect mesmo quando esta está presente (Castle 1993: 2). Jagose recupera esta ideia, salientando ainda o problema do lesbianismo quer na representação quer na representatividade, assim 
como a difícil relação ambivalente entre a lésbica e o campo de visão (Jagose 2002: 2) - ser vista como a incrível mulher teta é ser realmente vista?

Torna-se assim importante, segundo Jagose, indagar sobre os mecanismos estruturais da invisibilidade lésbica, que a produzem como uma imagem negativa e um reverso de convenções culturais que naturalizam a heterossexualidade e a sexualidade visíveis, à medida que se interrogam e transformam as estruturas que designam o lesbianismo como uma sexualidade de segunda ordem (ibidem). 0 lesbianismo parece então ser representado fora do campo visual da sexualidade exatamente porque a feminilidade não pode ser registada a não ser como uma ausência, como um negativo dentro de um modelo de desejo imaginado a partir do falo, sendo necessário defini-lo pelo que é em si mesmo sem referência ao seu outro sexual. Mais do que uma ausência, a lésbica ocupa uma posição simbolicamente liminal; é uma presença que não consegue ser vista e que marca os limites da visibilidade cultural da sexualidade, dada a sua opacidade epistemológica (idem: 3). Por isso, Jagose, expandindo o argumento de Rosi Braidotti, que o lesbianismo não pode ser uma sexualidade visível dado que os termos representacionais disponíveis não são seus, para além de se encontrar permanentemente dependente da derivação para a sua figuração (Jagose 2002: 7). Na introdução à Cambridge Companion for Lesbian Literature, Jodie Medd pergunta ainda:

Can women's sexual acts, or even erotic desire, be thought outside of heteronormativity or phallocentrism? What constitutes the evidential "proof" of sexual, erotic, or affective passion between women? Within systems of representation, which some argue are constituted as/through (sexual) difference, is the representation of desire between women even possible? And what do we mean by the term "woman," anyway? (Medd 2015: 2)

A "Mulher de Vermelho" de Angélica Freitas parece ser o encorporamento da "mulher" no espaço público, correspondendo à mulher-imagem do imaginário coletivo patriarcal, onde esta apenas se torna visível quando, à semelhança da namorada com a blusa transparente, é escrutinada pelo male gaze: 


\begin{abstract}
o que será que ela quer
essa mulher de vermelho

alguma coisa ela quer

pra ter posto esse vestido

não pode ser apenas

uma escolha casual

podia ser um amarelo

verde ou talvez azul

mas ela escolheu vermelho

ela sabe o que ela quer

e ela escolheu vestido

e ela é uma mulher

então com base nesses fatos

eu já posso afirmar

que conheço o seu desejo

caro watson, elementar:

o que ela quer sou euzinho

sou euzinho o que ela quer

só pode ser euzinho

o que mais podia ser

(Freitas 2018: s/p)
\end{abstract}

Para a voz masculina do poema, esta mulher de vermelho apenas existe em relação a si e para si, excluindo sequer a possibilidade de esta ser ainda um objeto de desejo para outra mulher; o livre arbítrio da mulher e a decisão consciente (ou não) de vestir o vestido vermelho é assim transformada numa investida sexual por parte da mulher, um convite ao olhar do Outro, incentivando a culpabilização da mulher por esta despertar desejo no sujeito poético, que por sua vez funciona como sinédoque para todos os homens que desejam esta mulher e invadem o seu corpo através do olhar. Tal lembra-nos da culpabilização constante de mulheres que são vítimas de assédio e violação ou ainda do movimento Slut Walk, uma reivindicação de que a roupa de uma mulher não poderá ser entendida de forma alguma como um convite ao abuso. Como Ivánova escreve num poema sobre uma violação: 


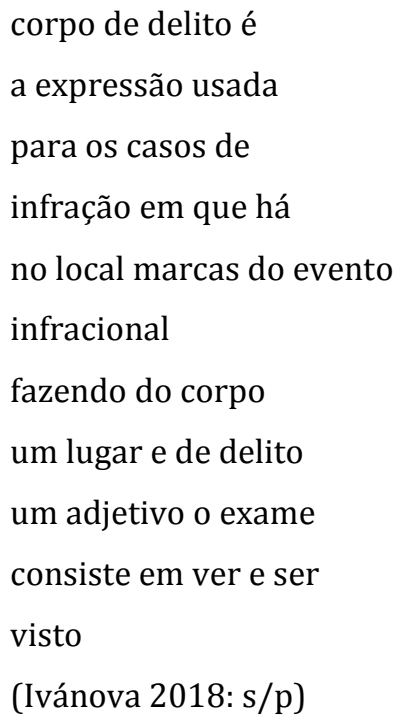

O corpo é então um lugar onde confluem discursos sociais e políticos e ter um corpo é "estar presente", é ver e ser visto, numa ação possivelmente invasiva por parte do Outro. Num outro poema, Ivánova apresenta-nos "a mulher de burca" que, ao ser tornada invisível e anulada como possível objeto de desejo, ao contrário da mulher de vermelho, torna-se visível por dar corpo à imagem da Outra, sempre exótica e incompreendida, salientando diferenças entre a mulher ocidentalizada e aquela que está debaixo da burca:

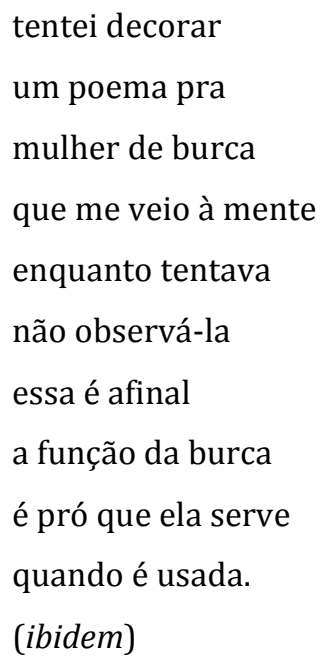


À semelhança do que acontece com a mulher de vermelho, "embaixo da burca/há uma mulher", por isso o poema de Adelaide Ivánova salienta a corporalização e a presença destas mulheres como corpos inscritos de significado dentro de uma matriz ocidental e heterossexual. Esta matriz reduz essas mulheres com identidades individuais a uma ideia, a uma categoria e a um corpo, por vezes apenas a um objeto sexual, outras vezes, à total aniquilação identitária. Adelaide Ivánova apela assim a um reconhecimento da mulher da burca, a um feminismo coletivo e transnacional, preocupado com todas as mulheres quando confrontadas com as leis ditadas pelos homens que regulam o corpo, ao definir regras de comportamento sexual ou até de indumentárias, como a longa discussão sobre o uso ou a proibição do véu em espaços públicos:

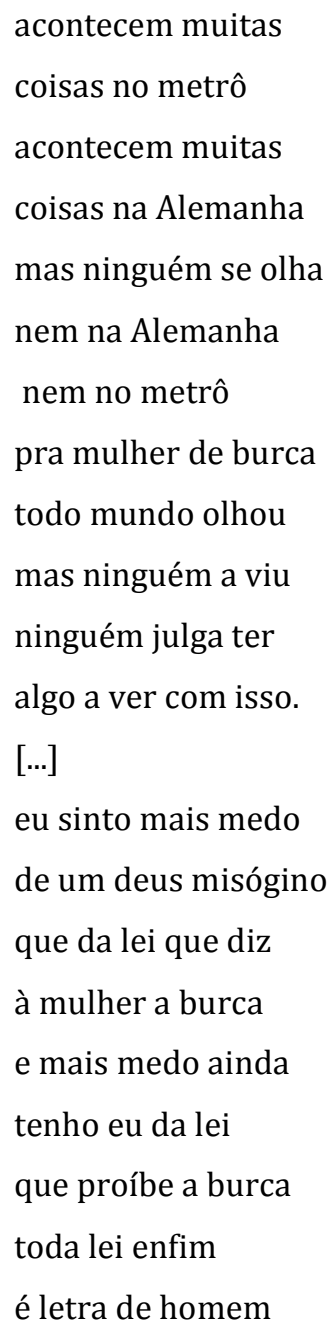


regulando corpos

(ibidem)

Termina-se este breve estudo com Ana Cristina Cesar (1952-1983), nome incontornável da poesia brasileira e uma das suas vozes mais transgressoras, "marginal entre marginais" (Frias 2005: 13), cujo poema "Ameno Amargo" oferece o título a este artigo:

Nós do mesmo sexo não

fabricamos delícias:

coçamos amenidades,

a tensão dos ângulos

distantes.

Com muitos dedos

puxamos as cortinas para trás.

Os sonhos não circulam.

O jogo está suspenso por decreto.

(Cesar 2013: 371)

São os dedos que escrevem o poema os mesmos que estimulam os genitais femininos; os dedos de Cesar, e daquelas "do mesmo sexo", relevam a identidade feminina e tornam-na visível ao mundo, afastando as várias cortinas, véus, vestidos vermelhos, blusas transparentes e burcas que escondem a mulher, ao evocar a erotização do corpo como a única forma de resistir à violência de outros dedos tais como aqueles da mão pesada masculina à qual Elza se refere, em "Maria da Vila Matilde”, como uma

Mão cheia de dedo
Dedo cheia de unha suja
E pra cima de mim? Pra cima de moi? Jamé, mané!
Cê vai se arrepender de levantar a mão pra mim.

(Soares 2015) 


\section{NOTAS}

1 [“derivação, imitação e secundarização. [...] [E] oculta dos principais enquadramentos teóricos, marginalizada nos campos onde figura, e considerada irrelevante para questões disciplinares centrais] (Tradução minha).

2 [“[A] investigação e a crítica feministas que contribuem para a invisibilidade ou marginalidade lésbica estão de facto a trabalhar contra a libertação e o empoderamento da mulher enquanto grupo"] (Tradução minha).

\section{Bibliografia}

Castle, Terry (1993), The Apparitional Lesbian: Female Homosexuality and Modern Culture, New York, Columbia University Press.

Cesar, Ana Cristina (2013), Poética, São Paulo, Companhia das Letras.

Freitas, Angélica (2017), O Útero é do Tamanho de Um Punho, Lisboa, Douda Correria [2012].

Frias, Joana Matos (2005), “Um verso que tivesse um blue”, in Ana Cristina Cesar, Um beijo que tivesse um blue, Famalicão, Quasi Edições, 7-17.

Ivánova, Adelaide (2018), O Martelo, Lisboa, Douda Correria [2017].

Jagose, Annamarie (2002), Inconsequence: Lesbian Representation and the Logic of Sexual Sequence, Ithaca and London, Cornell University Press.

-- (2015), "Debating Definitions: The Lesbian in Feminist Studies and Queer Studies", in 
Jodie Medd (ed.), The Cambridge Companion to Lesbian Literature, New York, Cambridge University Press, 32-44.

Medd, Jodie (2015), “Lesbian Literature?: An Introduction”, in J. Medd (ed.), The Cambridge Companion to Lesbian Literature, New York, Cambridge University Press, 1-16.

Rich, Adrienne (2003), “Compulsory Heterosexuality and Lesbian Existence”, Journal of Women's History, vol. 15, no. 3, Autumn, 11-48 [1980].

Soares, Elza (2015), A Mulher do Fim do Mundo, Circus/Natura Musical.

Sontag, Susan, (2004), Regarding the Pain of Others, London, Penguin Books, [2003].

Ana Bessa Carvalho é leitora na Universidade do Minho, Braga, no Departamento de Estudos Ingleses e Norte Americanos. É licenciada em Línguas e Literaturas Europeias e encontra-se a preparar uma Tese de Doutoramento sobre Estudos Queer e Literatura Comparada. Alguns dos seus poemas foram já publicados em antologias coletivas, como We Will Be Shelter: Poems for Survival (Ed. Andrea Gibson, Los Angeles: Write Bloody Publishing, 2014); Pombos Lerdos (Ed. Manuel Domingos, Coimbra: Medula, 2018); Casa (Ed. Maria Sousa, Coimbra: do lado esquerdo, 2016); e em revistas online (Enfermaria 6). 